Boise State University

ScholarWorks

$12-1-2017$

\title{
Sport Experiences of Division I Collegiate Athletes and Their Perceptions of the Importance of Specialization
}

Eric M. Martin

Boise State University

Martha E. Ewing

Michigan State University

Evelyn Oregon

Western Kentucky University 
This is an author-produced, peer-reviewed version of this article. The final, definitive version of this document can be found online at High

Abilities Studies, published by Routledge. Copyright restrictions may apply. doi: 10.1080/13598139.2017.1292894

\title{
Sport Experiences of Division I Collegiate Athletes and Their Perceptions of the Importance of Specialization
}

\author{
Eric M. Martin \\ Boise State University \\ Martha E. Ewing \\ Michigan State University \\ Evelyn Oregon \\ Western Kentucky University
}

\begin{abstract}
The purpose of the current study was to investigate Division I athletes' prior sport participation and athletes' perceptions regarding sport specialization. Athletes $(\mathrm{N}=1041)$ completed selfreport surveys and indicated that participation in their collegiate sport began around 9 years of age $(M=9.10, S D=3.83)$. Athletes played a large number of sports in elementary and middle school with participation decreasing during high school. For those athletes who specialized in one sport, specialization occurred typically at 12.5 years of age. In addition, athletes past sport background and perceptions of specialization differed depending on their college sport with some sports (i.e., gymnastics) starting participation and specializing earlier than others (i.e., football, cross country, and track and field). Interestingly, no differences existed in past sport experiences or perceptions of specialization dependent on scholarship status or expected playing status. This study supports prior research that early specialization is not a requirement for elite level performance.
\end{abstract}

Keywords: collegiate athletes, sport, elite, specialization

Many youth athletes who are striving for high-level achievement are confronted with the choice of playing multiple sports or to focus their time and training efforts solely on one sport. Athletes who choose to specialize typically participate in a single sport on a year-round basis, with a focus on training and development in that single sport (Wiersma, 2000). Often, athletes feel pressure to specialize and play one sport on a year-round basis from club or school coaches who desire more practice hours in their sport and year-round training (Watts, 1999), overzealous parents, and even themselves if they believe that the only way to gain a collegiate scholarship is through early specialization (Gould, Carson, Fifer, Lauer, \& Benham, 2009). However, even though the awareness around specializing in one sport in order to gain a college scholarship has increased recently, the concept of early specialization is not new. In fact over twenty years ago, Hill and Simons (1989) stated that in high school, one-sport athletes were rapidly replacing three-sport athletes. Even though research has been conducted investigating sport specialization (Baker, 2003; Baker, Cobley, \& Fraser-Thomas, 2009), there is still much that we do not know about the phenomenon including how elite athletes view specialization, whether the pathways for male and female athletes in the same sport differ, and if elite-level sport choice influences past sport experiences. Continued research on the differing paths to elite sport achievement is critical to inform athletes, coaches, and parents of the best practices for reaching these high levels of performance.

Due to the unique structure of the United States sporting system, it is especially important to understand athletes' pathways to elite level sport. Where most non-US sport systems receive guidance from a sport ministry or national sport governing body, there is no national minister of sport in the United States, and many sports either do not have a governing body or the governing body is limited in its decision making powers. In systems outside the United States, high level youth athletes are often placed into youth sport systems that are under the purview of a professional club or receive support from a governing body. These youth teams typically have a guiding philosophy and training principles to ensure youth are receiving proper instruction and care while playing in the system. 
However, in the United States, this type of model is rare. Youth identified with high sport potential often play on pay-to-play travel teams with little guidance from upper division clubs or a governing body. Additionally, even though high level youth often play for a high school team representing their school, they are also playing for a club team unaffiliated with any school. The one sport that is the exception to this general structure in the United States is American Football. Due to the cost associated with equipment, injury risk, and legal liability, a majority of football leagues are still largely associated with school teams and thus, do not have club teams that play outside of the school sport season.

After high school in the United States, opportunities for organized sport participation are extremely limited with college sport participation being one of the only avenues for continued organized competitive participation. A recent National Collegiate Athletic Association (NCAA) release (2015) indicated only 5.6\% of male athletes and 5.8\% of female athletes will participate in organized competitive sport at the collegiate level. In the NCAA, there are multiple levels of competition, with the highest level being Division I. Of those athletes who will play at the collegiate level, only $2.1 \%$ of male athletes and $1.9 \%$ of female athletes will participate at the Division I level where a majority of athletic scholarships are awarded. Due to the low number of athletes who participate in college sport, becoming a college athlete and performing at this elite level is held in high regard by many coaches, parents, and athletes (Farrey, 2008). In fact, for some athletes and parents, one major goal of sport participation is becoming a college athlete (Dorsch, Smith, Wilson, \& McDonough, 2015). Because the United States sporting structure is unique in regards to others across the world, further study on the pathways of these elite-level athletes who are competing at the Division I level, especially in regards to pathways to talent development in sport is needed.

Many theories have been proposed for talent development that include sport specialization (for a complete review see Alfermann \& Stambulova, 2007). The most prominent conceptualization of athletes' development in sport is the Developmental Model of Sport Participation (DMSP; Côté, 1999). Two key features of the DMSP are the concepts of deliberate play and deliberate practice. Deliberate play involves activities that are intrinsically motivating, provide immediate gratification, and are specifically designed to maximize enjoyment. Conversely, deliberate practice is characterized by training that generates no immediate rewards and requires physical and mental energy. Athletes are motivated by the goal of improving performance rather than inherent enjoyment. In the DMSP, the researchers posit four distinct stages of talent development: sampling years, specializing years, investment years, and the maintenance years. During the sampling years, athletes are involved in a large number of sports and sporting opportunities with experiences rooted in a high level of deliberate play and low levels of deliberate practice. The second stage in the DMSP is the specializing years. In the specializing years, athletes' deliberate play and practice are balanced, and athletes typically reduce their involvement in several sports. Following the specializing years, athletes enter the investment years characterized by high amounts of deliberate practice, low levels of deliberate play, and a focus on only one sport. In the DMSP, Côté proposed two paths to elite performance: elite performance through sampling a variety of sports and elite performance through early specialization in one sport. Elite performance through sampling involved progression through the three stages where athletes sampled a variety of sports, limited sport involvement to a few select sports, and finally complete devotion to a single sport. Elite performance through early specialization involved a focus on one sport very early, thus bypassing the sampling stage in sport. Côté hypothesized that both paths could lead to elite level sport involvement, but through sampling, athletes would experience greater enjoyment in sport and decreased physical and emotional health detriments.

Even though early sport specialization has been associated with many negative consequences, many believe that specialization is necessary for elite sport achievement. With such a small percentage of athletes reaching the highest level and the need for large amounts of practice to achieve expertise, parents and athletes may believe that extra exposure to a single sport may result in increased chances of elite skill achievement. In an investigation of experts from a variety of domains, Ericsson and colleagues (Ericsson, Krampe, \& Tesch-Romer, 1993) found that experts typically had a minimum of 10 years of experience in their chosen field. Additionally, Ericcsson and colleagues found that, through estimates of weekly practice, professional violinists had accumulated over 10,000 hours of deliberate practice.

Several in the media have focused on this 10,000 hours as a requirement for developing expertise. Even though some support in certain domains exists, the 10,000 hour requirement has many issues in the sport context. Researchers have shown that even though elite performers have trained more than near-elite performers, the elite sport performers fell short of the 10,000 practice hours that Ericsson proposed (Van Rossum, 2000). Further, 
This is an author-produced, peer-reviewed version of this article. The final, definitive version of this document can be found online at $\mathrm{High}$ Abilities Studies, published by Routledge. Copyright restrictions may apply. doi: 10.1080/13598139.2017.1292894

reducing the achievement of sport excellence to solely practice hours overlooks the importance that developmental, psychosocial, and motivational factors play in the achievement of high level success in youth (Baker \& Côté, 2006). Additionally, there is no direct research evidence that specialization in a single sport is more beneficial to the physiological development of an athlete than participating in multiple sports (Kaleth \& Mikesky, 2010), and it may in fact be detrimental to youth athletes. Myer and colleagues (2015) found that degree of specialization is positively correlated with increased serious risk for overuse injury and the American Medical Society for Sports Medicine released a position statement (DiFiori et al., 2014) indicating early sport specialization increases risk for overuse injury and burnout.

Multiple studies have shown that there are a variety of pathways that lead to elite status in sport. In a study of British athletes, Bridge and Toms (2013) found that over two-thirds of elite athletes were involved in their sport by the age of 11. However, a majority of these athletes were not involved in their primary sport at the age of 7 (25\%) or 9 (43\%). Further, athletes who played three sports at age 11, 13, and 15 had significantly higher likelihood of playing on a national team instead of a club team at the ages of 16 and 18. Côté, Lidor, and Hackfort (2009) argued that engaging in a variety of sports allows athletes to experience different physical, cognitive, affective, and psychosocial environments that promote the development of intrinsic motivation. The previously cited research provides support that individuals who play multiple sports have a greater advantage to reach the elite level of sport than those who play only one sport in youth. Even though much of the literature supports delayed specialization and multisport participation, more research on collegiate athletes' views of early specialization, their prior sport participation, and its importance on their own development is needed.

Multiple studies have investigated the prior participation backgrounds of elite level sport athletes (Bridge \& Toms, 2013; Côté, Lidor, \& Hackfort, 2009); however, the youth sport participation of United States collegiate athletes is lacking. High-level athletes have a unique perspective on what activities have helped their sport development, and their perspectives on youth specialization in sport should be further investigated. Therefore, the primary purpose of the study was to gain a better understanding of Division I athletes' prior sport experience including when athletes began participation in their collegiate sport, age of specialization, and prior sport participation along with number of sports played during youth. The second purpose investigated athletes' perceptions of the importance of sport specialization to becoming a Division I athlete. For both purposes, in addition to looking at past sport experiences in the total sample, differences were also investigated in relation to college sport, current scholarship status, and expected playing time for the upcoming season.

\section{Method}

\section{$\underline{\text { Participants }}$}

Participants were 1041 NCAA Division I student-athletes recruited from three Midwestern universities. The goal of the current study was to survey all participants from each university to gain an understanding of Division I athletes' previous sport participation. Five athletes were excluded because of incomplete surveys resulting in 1036 surveys in the final analyses. Athletes participated in a variety of collegiate sports including football $(\mathrm{n}=206)$, track and field $(n=114)$, soccer $(n=109)$, cross country $(n=73)$, swimming and diving $(n=72)$, baseball $(n=65)$, wrestling $(\mathrm{n}=64)$, basketball $(n=51)$, golf $(n=46)$, tennis $(n=42)$, rowing $(n=39)$, gymnastics $(n=37)$, volleyball $(n=31)$, field hockey $(n=27)$, hockey $(n=20)$, softball $(n=20)$, figure skating $(n=11)$, and not specified $(n=9)$. There were 559 male and 466 female athletes, and 11 athletes did not specify their sex in the final sample. The majority of the participants were Caucasian $(n=733 ; 70.8 \%)$ and African-American $(n=184 ; 17.8 \%)$ with the remainder of the sample being Asian $(n=15 ; 1.5 \%)$, Hispanic $(n=27 ; 2.6 \%)$, International $(n=30 ; 2.9 \%)$, and other $(n=47,4.5 \%)$. All academic grade classifications were represented (Freshman $n=292$, Sophomore $n=268$, Junior $n=252$, Senior $n=163,5^{\text {th }}$ year senior $n=49$, grad student $n=8$, and not specified $n=4$ ). Athletes were split between whether they were receiving a scholarship for sport participation with athletes either receiving a full scholarship $(n=382)$, partial scholarship $(n=384)$, or no funding $(n=270)$. Finally, more than half of all athletes indicated that for the upcoming season they expected to start or play a significant role on the team $(n=777)$, while others indicated they would play very little $(n=93)$, not play at all $(n=23)$, redshirt for medical reasons or to gain experience in the college environment $(n=86)$, or did not indicate playing status $(n=57)$. 
This is an author-produced, peer-reviewed version of this article. The final, definitive version of this document can be found online at $\mathrm{High}$ Abilities Studies, published by Routledge. Copyright restrictions may apply. doi: 10.1080/13598139.2017.1292894

\section{$\underline{\text { Measures }}$}

Participants completed a survey designed by the researchers and validated by known experts in the field. Experts in the field (coaches, former collegiate and professional athletes, and researchers familiar with research on sport specialization) all examined the final survey and believed that the survey was designed in a manner to answer the research questions of the study. Following examination by experts, the survey was pilot tested with former college athletes and current college students who did not play collegiate sport but were high school athletes, to ensure readability and comprehensiveness. The survey contained questions about demographics, prior sport experience, frequency of participation in sport-related activities, and perception of importance for sports activities and specialization.

\section{Demographics}

The demographics section assessed academic grade level, gender, race/ethnicity, mother's and father's highest level of education, collegiate sport experience, playing status, and scholarship status. Athletes were also asked the age when they first played their primary sport at an organized/competitive level. For all questions, athletes chose the response that most closely matched their experiences and current level in sport.

Sport participation. Previous sport experience was measured for all participants. Participants were provided a list of 22 sports and asked to circle when they played their sport, (i.e., elementary school, middle school, freshman, sophomore, junior, and senior years). In addition to the most common 22 sports listed on the sport experience sheet, a space was provided for "other" sports that athletes could designate if non-traditional sports were played.

Perceptions of specialization. The final section of the survey contained five questions that assessed the athletes' perception of specialization in sport. Specifically, athletes were asked to designate whether they specialized in sport prior to college, and if so, the sport in which they specialized and at what age specialization occurred. Athletes also responded to two questions that assessed their perceptions of the importance of specialization (1) prior to freshman year in high school and (2) at any time during high school. The question read "To what extent do you think that specializing in a sport (before freshman year in high school) and (at any time in high school) is necessary to become a Division I athlete?" A nine-point Likert-type response scale was used with response choices ranging from "Not at all important" (1) to "Very Important" (9). Reliability of retrospective information

A concern with studies that collect retrospective recall data is the accuracy of responses. Sports participation has a tendency to be structured and habitual over time, both of which may improve reliability of recall (Dex, 1991). Researchers have demonstrated that accuracy of recurrent events of significant importance such as sports, has high recall reliability (Friedenreich, Courneya, \& Bryant, 1998). Many studies have used recall design with prior sports participation with success. In studies with high level athletes, Leite and colleagues (Leite, Baker, \& Sampaio, 2009; Leite \& Sampaio, 2012) found that athletes who filled out questionnaires on youth sport participation had complete agreement on a one-month retest of the survey, and players and players' parents had complete agreement on the number of sports played at each age. Collectively, these past uses of retrospective recall with high success indicate that the use of recall in the current study is reasonably valid and reliable.

\section{Procedure}

Following permission from the university's institutional review board, approvals from athletic directors (AD) were attained for data collection. Collection was conducted in person at two universities, and one online collection was done at a third per the request from the AD. Surveys were distributed and completion of the surveys took between 10 and 20 minutes. For the online data collection, e-mails were sent to prospective participants by an academic adviser with two reminder e-mails sent a week apart.

\section{Results}

When investigating the descriptive statistics, it appeared that several of the sports varied in relation to several of the dependent variables. Therefore, descriptive statistics are presented for not only the total sample but also for each sport. In addition, as several of the sports had both male and female participants (i.e., basketball, cross country, golf, soccer, swimming and diving, tennis, and track and field), initial tests were conducted to see if there were 
This is an author-produced, peer-reviewed version of this article. The final, definitive version of this document can be found online at High Abilities Studies, published by Routledge. Copyright restrictions may apply. doi: 10.1080/13598139.2017.1292894

differences between gender within each sport. Multiple MANOVAs were conducted to see if there were gender differences within sport on number of sports played at each level of school, perceptions of specialization, and age when specialization occurred. Using a criterion of $p<.01$, no significant differences existed within any of the sports in relation to the dependent variables. Therefore, any sport that represented both male and female athletes was treated as a single sport in subsequent analyses. Finally, as there were several sports with a low number of athletes, only sports with 35 or more participants were included in subsequent analyses (these included baseball, basketball, cross country, football, golf, gymnastics, rowing, soccer, swimming and diving, tennis, track and field, and wrestling). These analyses used $p<.05$ as the criterion for indicating significant differences. Additionally, due to the high number of comparisons that were made for the analyses, Scheffe post hoc tests were employed to limit Type I error in the analyses because they adjust the size of critical value to determine if observed values are significantly different (Huck, 2012).

\section{Sport Experiences of Division I Athletes}

Age of First Sport Involvement. The average age for youth to enter their collegiate sport was around 9 years of age $(M=9.10, S D=3.83)$. A $12 \times 3 \times 5$ three-way ANOVA (sport, scholarship status, and projected playing time) was conducted to see if there were differences in regards to when athletes started their sport. Investigation of the interactions between the three grouping variables showed that all interaction effects were non-significant. The ANOVA revealed there were no differences in how early athletes participated in their sport by scholarship status $(F$ $\left.(2,680)=2.49, \mathrm{p}>.05, \eta^{2}=.01\right)$ or expected playing time $\left.F(4,680)=1.78, \mathrm{p}>.05, \eta^{2}=.01\right)$. However, there were significant differences in how early athletes began their sport depending on their current varsity sport, $F(11,680)=$ $23.98, \mathrm{p}<.001, \eta^{2}=.28$. Follow up Scheffe tests indicated several differences (see Table 1 for all differences). In general, athletes in gymnastics, baseball, soccer, wrestling and tennis started playing their collegiate sport when they were the younger than most groups and those athletes in rowing started participation in their sport when they were older than most other groups.

Age at Specialization. When examining only athletes who indicated they had specialized in one sport prior to college $(N=432)$ the mean age was $12.43(S D=3.78)$. To investigate if there were differences between age of specialization for specific sports, a univariate ANOVA was significant $\left(F(11,366)=9.16, p<.001, \eta^{2}=.22\right)$. Follow up Scheffe tests indicated that the group was more similar in their age of specialization than they were different (see Table 1 for all differences). When looking at athletes who specialized, there were no differences when specialization occurred between athletes in wrestling, soccer, basketball, swimming and diving, football, rowing, golf, and cross country. Differences emerged for those athletes specializing in gymnastics and track and field as gymnasts specialized earlier than other groups and athletes in track and field specialized older than other groups.

Sport Participation in Youth. For the sample, multi-sport participation was relatively high in elementary and middle school and steadily decreased from 3.17 sports per year to 1.64 sports per year as they continued through high school (see Table 2 for complete description). Even though participation decreased during high school, the average number of sports played during senior year is closer to two sports than one sport. In fact, when looking at frequency distributions, more athletes participated in multiple sports during their senior year than single sports. A 12 X 3 X 5 three-way MANOVA (sport, scholarship status, and projected playing time) was conducted to see if there were differences in athlete's past playing experience. Investigation of the interactions between the three grouping variables showed that all interaction effects were non-significant. Additionally, the MANOVA indicated there were no significant differences in the number of sports played at various levels dependent on scholarship status $(F$ (12, $\left.749)=1.25, \mathrm{p}>.05, \eta^{2}=.01\right)$ or expected playing status $\left(F(6,751)=1.10, \mathrm{p}>.05, \eta^{2}=.01\right)$. However, the MANOVA investigating prior sport participation in regards to the 12 individual sports (i.e., baseball, basketball, cross country, football, golf, gymnastics, rowing, soccer, swimming and diving, tennis, track and field, and wrestling) was significant, $F(11,753)=1.74, \mathrm{p}<.001, \eta^{2}=.03$. Univariate ANOVA follow up tests were also significant for each of the years of participation. For the elementary school $\left(F(11,753)=1.87, \mathrm{p}<.05, \eta^{2}=.03\right)$ and middle school years $\left(F(11,753)=3.27, \mathrm{p}<.001, \eta^{2}=.05\right)$, athletes in gymnastics participated in fewer sports than most other athletes with little variation between other sports in level of sport participation. In high school, this differentiation of groups became more pronounced. The univariate ANOVAs for freshman $(F(11,753)=3.99$, p < $\left..001, \eta^{2}=.06\right)$, sophomore $\left(F(11,753)=3.30, \mathrm{p}<.001, \eta^{2}=.05\right)$, junior $\left(F(11,753)=3.24, \mathrm{p}<.001, \eta^{2}=.05\right)$, and senior years of high school $\left(F(11,753)=2.68, \mathrm{p}<.001, \eta^{2}=.04\right)$ were all significant. In general, gymnasts participated in fewer sports than most other athletes. In addition to the differences seen in gymnasts, tennis athletes 
This is an author-produced, peer-reviewed version of this article. The final, definitive version of this document can be found online at High Abilities Studies, published by Routledge. Copyright restrictions may apply. doi: 10.1080/13598139.2017.1292894

and soccer players differed from most other sports as they participated in fewer sports during high school. Finally, athletes in football, cross country, and track and field consistently played more sports than several other athlete groups. For complete descriptions of number of sports played during each age see Table 3 .

Athlete Perceptions of Specialization. Even though participation rates indicated that a majority of athletes participated in more than one sport until senior year of high school, the number of athletes who perceived they specialized in one sport prior to college was evenly split (49.5\% indicating yes, $50.5 \%$ indicating no, respectively). The chi-square test analyzing the three groups and rates of specialization was significant, $\mathrm{X}^{2}(11, n=869)=117.09$, $p<.001$. More specifically, athletes in football indicated that they specialized at a significantly lower rate than expected, while athletes in gymnastics, soccer, and tennis specialized at a higher rate than expected for the sample (see Table 1 for exact values).

\section{Division I Athletes' Perceptions of Sport Specialization}

Athletes Perceived Importance of Specialization. The perceived importance of specializing for sporting success prior to high school was near the midpoint $(M=4.95 ; S D=2.76)$ of the 9-point scale indicating athletes on average viewed specialization as neither important nor unimportant. To investigate if there were differences in how athletes viewed the importance of specialization before high school and at any time during high school, a 12 X 3 X 5 threeway MANOVA (sport, scholarship status, and projected playing time) was conducted. Investigation of the interactions between the three grouping variables showed that all interaction effects were non-significant. Additionally, athletes' scholarship status $\left(F(2,724)=.10, \mathrm{p}>.05, \eta^{2}=.00\right)$ and expected playing status $(F(4,724)$ $\left.=1.81, \mathrm{p}>.05, \eta^{2}=.01\right)$ showed no significant differences in how they perceived the importance of specializing in sport. There was a significant difference in how athletes from various sports perceived specialization, $F$ (11, 724) $=2.59, \mathrm{p}<.001, \eta^{2}=.04$. Univariate ANOVA follow up tests were significant for perceived importance of specialization prior to high school $\left(F(11,724)=3.48, \mathrm{p}<.001, \eta^{2}=.05\right)$ and perceived importance at any time during high school $\left(F(11,724)=2.69, \mathrm{p}<.001, \eta^{2}=.04\right)$. Scheffe post hoc tests revealed that even though the group in general held similar perceptions of the importance of specialization prior to high school there were some differences between groups (see Table 3 for all differences). Athletes in baseball and football perceived the lowest importance of specialization prior to high school and athletes in soccer and gymnastics perceived the highest importance of specializing prior to high school. Interestingly, even though the univariate ANOVA indicated that there was a significant difference in how athletes perceived the importance of specialization at any point during high school, the Scheffe post-hoc tests indicated there were no significant differences between sports.

\section{Discussion}

Since Hill and Simmons (1989) reported on the disappearance of multisport athletes in high school sports, the benefits of sport specialization have been debated in the literature. The primary concern of specialization focuses on whether athletes are more likely to reach elite status by either limiting their sport involvement to only one sport at an early age or by playing multiple sports throughout childhood and adolescence. However, little research has been conducted with Division I athletes to assess which of these paths were beneficial in their own development. Therefore, the objective of this study was to provide empirical data for Division I collegiate athletes' previous sport experiences and their views on sport specialization.

Athletes in our sample typically played a variety of sports in the elementary and middle school ages with participation decreasing slightly with each year of high school. Even though the number of sports athletes participated in decreased, more athletes participated in more than one sport during their senior year than athletes who specialized in only one sport. The athletes' participation rates were similar to the path that Côtés Developmental Model of Sport Participation (1999) proposed. The DMSP proposed that athletes typically move through four distinct phases of sport participation including sampling, specializing, investing, and maintenance. In the DMSP, athletes engaged in a variety of sports during the sampling years (age 6-12), then focused on one or two with increasing specialization during the specializing years (age 13-16), and finally limited their participation to only one sport during the investment phase (age 16+). The pathways are similar, however, athletes in the current study moved to the investment phase only upon entering college and, therefore, were older than Côté proposed. The delayed specialization of elite level athletes was similar to other studies (Bridge \& Toms, 2013; Leite Baker, \& Sampaio, 2009; Leite \& Sampaio, 2012) that also found elite level athletes typically participated in a variety of sports as youth. Even though athletes in our sample participated in a variety of sports as youth, on average athletes 
This is an author-produced, peer-reviewed version of this article. The final, definitive version of this document can be found online at $\mathrm{High}$ Abilities Studies, published by Routledge. Copyright restrictions may apply. doi: 10.1080/13598139.2017.1292894

began participating in their primary sport at just over nine years of age. There was large variation in the sample in the age of initiation which indicates that some athletes started participation in their primary sport younger, while others started when they were older than nine years of age (Range $=2-19)$. All athletes in hockey (Range 3-8) and gymnastics (Range 2-10) were involved in their primary sport prior to age 10, while individuals in all other sports including basketball (Range 5 -18), soccer (Range 3 -18), and swimming (Range 4-18) had a more varied age of initiation with some athletes not starting participation until adolescence. The large variation of initiation into one's primary sport further mirrors other studies with British elite athletes in a variety of sports including track and field, soccer, hockey, netball, rugby, and swimming (Bridge \& Toms, 2013) and Portuguese athletes involved in soccer, volleyball, swimming, judo, and basketball (Barreiros \& Fonseca, 2012; Leite \& Sampaio, 2012) where there was large variation in ages of when athletes began playing their primary sport.

Even though anecdotal reports indicated that specialization has become an overwhelming issue in high school sports, the results of this study indicated that a majority of elite-level athletes are not specializing prior to college. From self-report data of past sport participation, over half of all athletes participated in more than one sport until their senior year of high school, and only $41 \%$ of the sample indicated that they perceived that they specialized in one sport prior to beginning their university participation. For those athletes who did specialize in sport, they did not specialize until they were, on average, 12.5 years of age. Further, athletes' perceptions of specialization importance prior to high school was directly at the midpoint of the scale indicating that they believed specializing in one sport was neither important nor unimportant. However, athletes' perception of the importance of specialization did increase as the athletes moved from freshman to senior year in high school. It is possible that as athletes begin to receive college coaches' and recruiters' attention in one sport, they may begin to see the value of specialization and believe that focusing on only one sport maximizes the potential for attaining a college scholarship. In sum, athletes on average did not specialize at an early age (prior to the age of 12) and further, they do not perceive early specialization to be critical for becoming a Division I athlete but the importance of specialization does increase during high school.

When first investigating gender differences within sports, no significant differences existed in our sample. In fact, in sports with both male and female athletes, analyses showed there were no significant gender differences in how many sports athletes played at each level of school, perceptions of specialization, and age at which specialization occurred.

Thus, athletes in our sample viewed sport participation and perceptions of specialization similarly, regardless of athletes' sex. These findings come in direct competition to Coakley (2008) who argued that many reasons may exist for female athletes' lower levels of participation in sport including girls feeling out of place in mixed gender leagues typically dominated by boys and decreased financial support for girls. It might be that gender differences may exist in the general population, but female athletes who reached elite levels had greater levels of competence and were not influenced by gender specific leagues, found female-only leagues for other talented girls, and had parents and significant others who supported their participation. These trends need to be further investigated to see if they are consistent across different samples or just localized to this particular one.

When investigating the differences in individual sports, a variety of unique aspects of each sport were present. First, the time athletes started their sport was influenced by the sport they ultimately played in college. Athletes in gymnastics, baseball, and soccer were some of the earliest to begin in their sport, while those athletes in cross country, track and field, and rowing were some of the latest to begin participation in their sport. Further, athletes in different sports showed variation in the number of athletes who specialized as well as the age in which they specialized. For example, gymnasts specialized earlier and had a higher percentage of athletes specialize in one sport than most other sports while athletes in football had the lowest rates of specialization and specialized later than many other sports. Finally, it appears that a majority of the athletes, regardless of collegiate sport, followed the path proposed by the DMSP (Côté, 1999) where specialization occurred in the first or second year of high school. Football players were one exception to the DMSP as they postponed single-sport participation until they entered the collegiate level. Finally, analyses indicated that there was high variation for how important athletes perceived specialization prior to entering high school. Athletes in baseball and football viewed specialization as the least important in comparison to other sports. Interestingly, even though athletes in baseball were some of the earliest to begin their sport, they were also one of the latest to specialize, had one of the lowest rates of specialization, and viewed specialization as less important for success, indicating that just because youth play a sport early does not necessitate early sport specialization. Additionally, and not surprisingly, gymnasts viewed specialization as most 
This is an author-produced, peer-reviewed version of this article. The final, definitive version of this document can be found online at High Abilities Studies, published by Routledge. Copyright restrictions may apply. doi: 10.1080/13598139.2017.1292894

important in comparison to other sports. As gymnastics is a sport where the age of peak performance is lower than others (Strachan, Côté, \&Deakin, 2009), the fact that gymnasts specialized earlier, at a higher rate, and viewed specialization as more important is not unexpected.

These sport differences may exist due to the different structures of the sport environments. In many sports, including basketball, volleyball, and soccer, year round participation is the norm with athletes participating on a high school team while also playing on club teams in the fall, winter, spring, and summer seasons. In football, with the exception of spring practices and various summer team camps (i.e., 7-on-7 camps), year round participation is much more difficult to achieve. Due to the physical nature of football, and the inability to play year round, coaches may actively encourage their athletes to participate in other sports to stay in shape and prepare for the next competitive football season. Additionally, cross-training in multiple sports may be beneficial in developing the skills required to play football at the Division I level. If these differences in sport participation are due to the structure of sports, the disappearance of single-sport athletes needs to be more closely investigated from the larger perspective. Further study needs to be done to see if this phenomenon is solely in this sample or is common across the student populations in other collegiate divisions (i.e., Division II, Division III, NAIA). Even though these groups did differ in a number of ways, for those athletes that did specialize prior to college, there were no differences in the age in which specialization occurred.

Lastly, although a non-significant finding, the fact that athletes did not differ on their past sport experiences and perceptions of the importance of specialization regardless of expected playing time and scholarship status is noteworthy. Both of these aspects are indirect markers of ability. Those athletes who receive higher levels of scholarship money and expect to play more frequently should, in theory, be the most skilled athletes in the sample. However, the fact that these athletes past sport experience and perceptions of the importance of sport specialization did not differ suggests that athletes who make it to this elite-level of competition, regardless of how skilled they are, have similar pathways to the Division I level. Further study on what factors impact these variables would be beneficial to truly understand what aspects may differentiate between athletes once they reach elite-levels of competition.

\section{Conclusion}

Prior research has investigated specialization in sport, but this study is unique in that no previous study has looked at the past sport experience of Division I athletes and investigated their perceptions of specialization. From a practical perspective, our study provides evidence that early specialization is not required to reach elite levels of sport. In our sample, more athletes participated in multiple sports than a single sport even during senior year of high school. For those athletes who specialized in one sport, they did not select one sport until they were 12.5 years of age and in the middle of the specializing phase of the DMSP. Therefore, even though specialization has increased in recent years, it appears that specializing in one sport is not a requirement for elite athletic success. In fact, participation in multiple sports may actually be beneficial for athletes. Parents, coaches, and athletes need to be educated about the value of multi-sport participation and the possible negative consequences of early specialization. Further, this study and others (Bridge \& Toms, 2013; Côté, Lidor, \& Hackfort, 2009) have demonstrated that early specialization is not a requirement for achieving elite level performance in a majority of sports. The fact many athletes and parents still feel the pressure to focus on only one sport to increase one's chances of obtaining a Division I scholarship or playing status was not substantiated in the present study. It needs to be investigated whether this pressure is sport specific and, if so, what structural changes can be made to dissuade athletes from specializing early. There is no one path to elite level athletics, and great variation exists in the number of sports youth played and the types of sport activities they participated in during youth. 
This is an author-produced, peer-reviewed version of this article. The final, definitive version of this document can be found online at High Abilities Studies, published by Routledge. Copyright restrictions may apply. doi: 10.1080/13598139.2017.1292894

\section{References}

Alfermann, D., \& Stambulova, N. (2007). Career transitions and career termination. In G. Tenenbaum \& R. C. Eklund (Eds.), Handbook of sport psychology, ( $3^{\text {rd }}$ ed., pp. 712-736). Hoboken, NJ: John Wiley \& Sons, Inc.

Baker, J. (2003). Early specialization in youth sport: A requirement for adult expertise? High Ability Studies, 14(1), $85-94$.

Baker, J. Cobley, S. Fraser-Thomas, J. (2009). What do we know about early sport specialization? Not much! High Ability Studies, 20(1), 77-89.

Baker, J., \& Côté, J. (2006). Shifting training requirements during athlete development: Deliberate practice, deliberate play and other sport involvement in the acquisition of sport expertise. In D. Hackfort and G. Tenenbaum (Eds.), Essential processes for attaining peak performance, (pp. 92-109). Oxford, UK: Meyer \& Meyer.

Barreiros, A. N., \& Fonseca, A. M. (2012). A retrospective analysis of Portuguese elite athletes' involvement in international competitions. International Journal of Sports Science and Coaching, 7(3), 593-600.

Bridge, M. W., \& Toms, M. R. (2013). The specialising or sampling debate: A retrospective analysis of adolescent sports participation in the UK. Journal of Sports Sciences, 31(1), 87-96.

Coakley, J. J. (2008). Sports in society: Issues and controversies (10 ${ }^{\text {th }}$ ed.). New York, NY: McGraw-Hill.

Côté, J. (1999). The influence of the family in the development of talent in sport. The Sport Psychologist, 13(4), 395-417.

Côté, J., Lidor, R., \& Hackfort, D. (2009). ISSP position stand: To sample or to specialize? Seven postulates about youth sport activities that lead to continued participation and elite performance. International Journal of Sport and Exercise Psychology, 7(1), 7-17.

Dex, S. (1991). The reliability of recall data: A literature review. Working papers of the ESRC Research Center of Micro-social change (Paper 11). Colchester, UK: Univ. Essex.

DiFiori, J. P., Benjamin, H. J., Brenner, J. S., Gregory, A., Jayanthi, N., Landry, G. L., \& Luke, A. (2014). Overuse injuries and burnout in youth sports: a position statement from the American Medical Society for Sports Medicine. British journal of sports medicine, 48(4), 287-288.

Dorsch, T. E., Smith, A. L., Wilson, S. R., \& McDonough, M. H. (2015). Parent goals and verbal sideline behavior in organized youth sport. Sport, Exercise, and Performance Psychology, 4(1), 19.

Ericsson, K. A., Krampe, R. T., Tesch-Romer, C. (1993). The role of deliberate practice in the acquisition of expert performance. Psychological Review, 100(3), 363-406.

Farrey, T. (2008). Game on: The All-American race to make champions of our children. ESPN.

Friedenreich, C. M., Courneya, K. S., \& Bryant, H. E. (1998). The lifetime total physical activity questionnaire: Development and reliability. Medicine and Science in Sports and Exercise, 30(2), 266-274.

Gould, D., Carson, S., Fifer, A., Lauer, L., \& Benham, R. (2009). Social-emotional and life skill development issues characterizing today's high school sport experience. Journal of Coaching Education, 2, 1-25.

Hill, G., \& Simmons, J., (1989). The study of the sport specialization on high school athletics. Journal of Sport and Social Issues, 13(1), 1-13.

Huck, S. W. (2012). Reading statistics and research (6th ed.). Boston, MA: Pearson Education.

Kaleth, A. S., \& Mikesky, A. E. (2010). Impact of early sport specialization: A physiological perspective. Journal of Physical Education, Recreation \& Dance, 81(8), 29-37.

Leite, N., Baker, J., \& Sampaio, J. (2009). Paths to expertise in Portuguese national team athletes. Journal of Sports Science and Medicine, 8(4), 560-566.

Leite, N. M., \& Sampaio, J. E. (2012). Long-term athletic development across different age groups and gender from Portuguese basketball players. International Journal of Sports Science and Coaching, 7(2), 285-300.

Myer, G. D., Jayanthi, N., Difiori, J. P., Faigenbaum, A. D., Kiefer, A. W., Logerstedt, D., \& Micheli, L. J. (2015). Sport specialization, Part I: Does early sports specialization increase negative outcomes and reduce the opportunity for success in young athletes? Sports Health. 7, 437-442.

NCAA.org. (February, 25, 2015). Estimated probability of competing in college athletics. Retrieved March 17, 2016, from http://www.ncaa.org/about/resources/research/estimated-probability-competing-college-athletics

Strachan, L., Côté, J., \& Deakin, J. (2009). " Specializers" versus" samplers" in youth sport: Comparing experiences and outcomes. Sport Psychologist,23(1), 77.

Van Rossum, J. (2000). Deliberate practice and Dutch field hockey: An addendum to Starkes. International Journal of Sport Psychology, 31, 452-460.

Watts, J. (1999). Perspectives on sport specialization. Journal of Physical Education, Recreation \& Dance, 73(8), $32-50$. 
This is an author-produced, peer-reviewed version of this article. The final, definitive version of this document can be found online at High Abilities Studies, published by Routledge. Copyright restrictions may apply. doi: 10.1080/13598139.2017.1292894

Wiersma, L. (2000). Risks and benefits of youth sport specialization: Perspectives and recommendations. Pediatric Exercise Science, 12(1), 13-22. 
Table 1

Means and standard deviations for the total sample and individual sports for age of first participation, average age of specialization for those athletes who indicated they specialized in one sport, and number of athletes who specialized

\begin{tabular}{|c|c|c|c|c|}
\hline & $\mathrm{n}$ & Age of first participation & Average age of specialization & $\begin{array}{c}\text { Number of athletes who } \\
\text { specialized }\end{array}$ \\
\hline Total Sample & 1031 & $9.10(3.83)$ & $12.43(3.78)$ & $432(41.9 \%)$ \\
\hline Football & 207 & $9.84(3.19)^{\mathrm{bc}}$ & $13.18(3.92)^{\mathrm{bcd}}$ & $38(18.4 \%)$ \\
\hline Track and Field & 114 & $12.43(2.67)^{\mathrm{d}}$ & $14.78(2.26)^{\mathrm{cd}}$ & $41(36.0 \%)$ \\
\hline Soccer & 110 & $6.10(2.46)^{\mathrm{a}}$ & $11.30(4.32)^{\mathrm{abcd}}$ & $70(63.6 \%)$ \\
\hline Cross Country & 73 & $12.26(2.43)^{\mathrm{cd}}$ & $13.52(2.50)^{\mathrm{bcd}}$ & $25(34.2 \%)$ \\
\hline Swimming and Diving & 72 & $8.76(3.61)^{b}$ & $12.56(3.04)^{\mathrm{abcd}}$ & $39(54.2 \%)$ \\
\hline Baseball & 65 & $5.95(2.79)^{\mathrm{a}}$ & $15.44(1.46)^{\mathrm{d}}$ & $18(27.7 \%)$ \\
\hline Wrestling & 64 & $7.49(3.60)^{\mathrm{ab}}$ & $11.10(4.37)^{\mathrm{abc}}$ & $30(46.9 \%)$ \\
\hline Basketball & 51 & $9.06(2.93)^{\mathrm{b}}$ & $12.17(3.74)^{\mathrm{abcd}}$ & $23(45.1 \%)$ \\
\hline Golf & 46 & $8.84(3.51)^{\mathrm{b}}$ & $13.45(2.84)^{\mathrm{bcd}}$ & $22(47.8 \%)$ \\
\hline Tennis & 42 & $7.53(2.41)^{\mathrm{ab}}$ & $10.04(3.38)^{\mathrm{ab}}$ & $27(64.3 \%)$ \\
\hline Rowing & 39 & $16.10(2.30)^{\mathrm{e}}$ & $13.28(3.16)^{\mathrm{bcd}}$ & $18(46.2 \%)$ \\
\hline Gymnastics & 37 & $5.62(1.83)^{\mathrm{a}}$ & $8.41(3.33)^{\mathrm{a}}$ & $27(73.0 \%)$ \\
\hline Volleyball & 31 & $10.17(2.93)$ & $14.35(2.17)$ & $16(51.6 \%)$ \\
\hline Field Hockey & 27 & $7.81(2.86)$ & $14.90(1.85)$ & $11(40.7 \%)$ \\
\hline Hockey & 21 & $5.24(1.45)$ & $12.64(4.14)$ & $18(85.7 \%$ \\
\hline Softball & 20 & $7.45(2.68)$ & $13.4(1.35)$ & $12(60.0 \%)$ \\
\hline Figure Skating & 11 & $9.88(2.30)$ & $9.50(3.73)$ & $6(54.5 \%)$ \\
\hline
\end{tabular}

Note: Within each column, means with the subscript "a" are significantly different than means with the subscripts "b" "c", and "d"; means with the subscript "b" are significantly different than means with the subscripts "c" and "d"; and means with subscript "c" are significantly different than means with subscripts "d" (as determined through Scheffe post-hoc tests [all $p \mathrm{~s}<.05])$. 
Table 2

Means and standard deviations of total sample and individual sports for number of sports played during each age period

\begin{tabular}{|c|c|c|c|c|c|c|c|}
\hline & $\mathrm{n}$ & $\begin{array}{c}\text { Elementary } \\
\text { School }\end{array}$ & $\begin{array}{l}\text { Middle } \\
\text { School }\end{array}$ & $\begin{array}{c}\text { Freshman } \\
\text { Year }\end{array}$ & $\begin{array}{c}\text { Sophomore } \\
\text { Year }\end{array}$ & $\begin{array}{c}\text { Junior } \\
\text { Year }\end{array}$ & $\begin{array}{c}\text { Senior } \\
\text { Year }\end{array}$ \\
\hline Total Sample & 1031 & $3.17(1.75)$ & $3.13(1.52)$ & $2.08(1.05)$ & $1.88(.96)$ & $1.71(.92)$ & $1.64(.92)$ \\
\hline Football & 207 & $2.82(1.59)^{\mathrm{ab}}$ & $2.99(1.43)^{\mathrm{bc}}$ & $2.43(1.02)^{\mathrm{d}}$ & $2.24(0.96)^{\mathrm{d}}$ & $2.13(0.93)^{\mathrm{e}}$ & $2.04(0.88)^{\mathrm{d}}$ \\
\hline Track and Field & 114 & $2.96(1.96)^{\mathrm{ab}}$ & $3.28(1.56)^{\mathrm{bc}}$ & $2.42(1.07)^{\mathrm{cd}}$ & $2.15(0.99)^{\mathrm{cd}}$ & $1.94(0.84)^{\mathrm{de}}$ & $1.86(0.93)^{\mathrm{bcd}}$ \\
\hline Soccer & 110 & $3.42(1.66)^{\mathrm{ab}}$ & $3.22(1.57)^{\mathrm{bc}}$ & $1.80(0.99)^{\mathrm{abcd}}$ & $1.50(0.77)^{\mathrm{abc}}$ & $1.24(0.68)^{\mathrm{abc}}$ & $1.26(0.64)^{\mathrm{ab}}$ \\
\hline Cross Country & 73 & $3.05(1.75)^{\mathrm{ab}}$ & $3.51(1.62)^{\mathrm{bc}}$ & $2.48(0.94)^{\mathrm{d}}$ & $2.25(0.74)^{\mathrm{cd}}$ & $2.08(0.47)^{\mathrm{de}}$ & $2.03(0.64)^{\mathrm{cd}}$ \\
\hline Swimming and Diving & 72 & $3.49(1.81)^{\mathrm{b}}$ & $2.94(1.35)^{\mathrm{bc}}$ & $1.63(0.89)^{\mathrm{abc}}$ & $1.53(0.84)^{\mathrm{abcd}}$ & $1.40(0.71)^{\mathrm{abcd}}$ & $1.31(0.66)^{\mathrm{abc}}$ \\
\hline Baseball & 65 & $3.60(1.47)^{b}$ & $3.53(1.23)^{\mathrm{bc}}$ & $2.42(0.85)^{\mathrm{cd}}$ & $2.17(0.89)^{\mathrm{cd}}$ & $1.92(0.85)^{\mathrm{cde}}$ & $1.78(0.82)^{\mathrm{bcd}}$ \\
\hline Wrestling & 64 & $3.13(1.79)^{\mathrm{ab}}$ & $2.73(1.29)^{\mathrm{bc}}$ & $1.88(0.93)^{\mathrm{abcd}}$ & $1.69(0.89)^{\mathrm{abcd}}$ & $1.58(0.79)^{\mathrm{abcde}}$ & $1.50(0.71)^{\mathrm{abcd}}$ \\
\hline Basketball & 51 & $2.80(1.66)^{\mathrm{ab}}$ & $3.02(1.45)^{\mathrm{bc}}$ & $1.82(0.95)^{\mathrm{abcd}}$ & $1.73(0.85)^{\mathrm{bcd}}$ & $1.63(0.89)^{\text {bcde }}$ & $1.43(0.73)^{\mathrm{abcd}}$ \\
\hline Golf & 46 & $3.67(1.59)^{b}$ & $3.43(1.41)^{\mathrm{bc}}$ & $1.93(0.85)^{\mathrm{bcd}}$ & $1.93(0.93)^{\mathrm{bcd}}$ & $1.59(0.86)^{\mathrm{abcde}}$ & $1.39(0.61)^{\mathrm{abcd}}$ \\
\hline Tennis & 42 & $2.61(1.96)^{\mathrm{ab}}$ & $2.56(1.60)^{\mathrm{ab}}$ & $1.49(1.40)^{\mathrm{ab}}$ & $1.34(1.13)^{\mathrm{ab}}$ & $1.15(1.21)^{\mathrm{ab}}$ & $1.51(1.58)^{\mathrm{abcd}}$ \\
\hline Rowing & 39 & $3.59(1.79)^{\mathrm{b}}$ & $3.90(1.55)^{\mathrm{c}}$ & $2.28(1.02)^{\mathrm{bcd}}$ & $1.95(0.94)^{\mathrm{bcd}}$ & $1.87(1.00)^{\mathrm{cde}}$ & $1.77(1.06)^{\mathrm{bcd}}$ \\
\hline Gymnastics & 37 & $2.03(1.36)^{\mathrm{a}}$ & $1.59(1.14)^{\mathrm{a}}$ & $1.08(0.36)^{\mathrm{a}}$ & $0.95(0.33)^{\mathrm{a}}$ & $0.89(0.31)^{\mathrm{a}}$ & $0.92(0.28)^{\mathrm{a}}$ \\
\hline Volleyball & 31 & $2.96(1.96)$ & $3.19(1.49)$ & $1.94(.93)$ & $1.87(.81)$ & $1.74(.82)$ & $1.55(.77)$ \\
\hline Field Hockey & 27 & $4.37(1.52)$ & $4.00(1.36)$ & $2.59(1.15)$ & $2.26(1.20)$ & $2.00(1.44)$ & $1.93(1.59)$ \\
\hline Hockey & 21 & $2.03(1.36)$ & $3.47(1.66)$ & $1.86(1.19)$ & $1.48(.75)$ & $1.29(.64)$ & $1.14(.57)$ \\
\hline Softball & 20 & $3.70(1.89)$ & $3.65(1.53)$ & $1.90(.72)$ & $1.65(.93)$ & $1.30(.73)$ & $1.15(.59)$ \\
\hline Figure Skating & 11 & $3.27(1.62)$ & $2.09(1.45)$ & $1.18(.40)$ & $1.27(.47)$ & $1.27(.65)$ & $1.09(.70)$ \\
\hline
\end{tabular}

Note: Within each column, means with the subscript "a" are significantly different than means with the subscripts "b","c", and "d"; means with the subscript "b" are significantly different than means with the subscripts "c" and "d"; means with subscript "c" are significantly different than means with subscripts "d"; and means with subscript "d" are significantly different than means with subscripts "e" (as determined through Scheffe post-hoc tests [all $p$ s < .05]). 
This is an author-produced, peer-reviewed version of this article. The final, definitive version of this document can be found online at High Abilities Studies, published by Routledge. Copyright restrictions may apply. doi: 10.1080/13598139.2017.1292894

Table 3

Means and standard deviations of total sample and individual sports for perceived importance of specialization before high school and anytime during high school.

\begin{tabular}{lccc}
\hline & $\mathrm{n}$ & $\begin{array}{c}\text { Perceived importance of specialization prior } \\
\text { to high school }\end{array}$ & $\begin{array}{c}\text { Perceived importance of specialization } \\
\text { at any point during high school }\end{array}$ \\
\hline Total Sample & 1031 & $4.95(2.76)$ & $6.61(2.44)$ \\
Football & 207 & $3.97(2.81)^{\mathrm{a}}$ & $5.63(2.82)$ \\
Track and Field & 114 & $6.15(2.29)^{\mathrm{abc}}$ & $6.38(2.40)$ \\
Soccer & 110 & $5.58(2.59)^{\mathrm{cd}}$ & $7.06(1.98)$ \\
Cross Country & 73 & $4.39(2.52)^{\mathrm{abc}}$ & $6.96(2.22)$ \\
Swimming and Diving & 72 & $6.32(2.59)^{\mathrm{abcd}}$ & $7.44(1.95)$ \\
Baseball & 65 & $4.00(2.74)^{\mathrm{ab}}$ & $5.76(2.72)$ \\
Wrestling & 64 & $5.73(2.95)^{\mathrm{abcd}}$ & $6.87(2.63)$ \\
Basketball & $5.45(2.75)^{\mathrm{abcd}}$ & $6.79(2.37)$ \\
Golf & 51 & $4.8(2.45)^{\mathrm{abc}}$ & $6.83(2.09)$ \\
Tennis & 46 & $4.62(2.50)^{\mathrm{bcd}}$ & $6.90(2.40)$ \\
Rowing & 42 & $4.33(2.61)^{\mathrm{abc}}$ & $6.10(2.09)$ \\
Gymnastics & $7.08(2.06)^{\mathrm{d}}$ & $7.51(1.73)$ \\
Volleyball & 39 & $3.77(257)$ & $6.74(1.91)$ \\
Field Hockey & 37 & $4.04(2.82)$ & $5.84(2.79)$ \\
Hockey & 31 & $5.10(2.59)$ & $6.05(1.99)$ \\
Softball & 27 & $6.30(2.58)$ & $7.95(1.10)$ \\
Figure Skating & 21 & $5.50(1.58)$ & $7.60(1.71)$ \\
\hline & 20 & &
\end{tabular}

Note: Within each column, means with the subscript "a" are significantly different than means with the subscripts "b","c", and "d"; means with the subscript "b" are significantly different than means with the subscripts "c" and "d"; means with subscript "c" are significantly different than means with subscripts "d" (as determined through Scheffe post-hoc tests [all $p$ s $<.05]$ ). 